\title{
A study on the correlation of the indoor and outdoor particulate pollution levels in the university premises
}

\author{
Yexuan Zhu \\ Department of Power Engineering, North China Electric Power University, Baoding 071000, China.
}

zhuyexuaner@163.com

Keywords: Particulate matter, Relevance, Mass concentration, Diurnal variation law

\begin{abstract}
In recent years, haze weather happens frequently. PM2.5 and PM10 are the main factors that affect the haze weather, so they deserve to be studied. The study will help to propose better measures to improve the indoor air quality. This paper is to study the relevance of indoor and outdoor concentrations of particulate matter, the daily variation of indoor particulate matter concentrations and the horizontal distribution law of particulate pollution in campus buildings. Through the study, it can be seen that outdoor particulate pollutants is the main source of indoor particulate matter and there is no significant difference in the average particle concentration between the daytime and night.
\end{abstract}

\section{Introduction}

The harm of particulate matter in the air is becoming more and more obvious nowadays. High concentrations of particulate matter in the air will damage the respiratory system [1] and lead to cardiovascular disease, cancer [2], etc. However, the time of modern 70\%-90\% is spent indoors [3], so indoor air quality is particularly important. The study is helpful for us to understand the change of the concentration level of particulate matter and improve the indoor air quality.

\section{Methods and materials}

Experimental subjects. One of experiments was taken place in the girl's dormitory. The experiment was to find out the relationship between indoor and outdoor particle concentration and the daily variation of indoor particulate matter concentrations. The room was on the second floor, and the area of it is about $28 \mathrm{~m}^{2}$. The length of the room is seven meters and the width of it is four meters. There is window, a door, six pieces of beds and tables, an air conditioner and a fan in it. For the comparison of particle concentration in campus buildings, a campus underground supermarket, canteens, teaching buildings, parks, computer rooms, toilets, wash rooms and a library were selected to be measured.

Experimental apparatus. In this experiment, the mass concentration of PM2.5 and PM10.0 was measured by DUSTTRAK 8520.

Experimental methods. The relationship between indoor and outdoor particle concentration levels: the experiment was conducted from $8: 00 \mathrm{am}$ to $8: 00 \mathrm{pm}$. The data was measured every one hour. Particulate mass concentration in the girl's dormitory was measured firstly. Then outdoor particulate mass concentration was measured immediately. The change of particle concentration in the whole day: this experiment needs all day measurements. The concentration of particulate matter in the dormitory was measured every one hour. The comparison of the concentration of PM2.5 in typical places of Campus: the experiment was done nearly at the same time, and each place was measured for a minute.

\section{The relationship between indoor and outdoor particle concentration levels}

The concentrations of indoor and outdoor particulate matter are closely related to each other. However, what is the exactly relationship between them is unknown. Therefore, this section is to find out the relationship. 
Indoor and outdoor particulate matter concentration ratio. There are two main methods for figuring out the concentration ratio of indoor and outdoor particulate matter [4].

Method one: integration method

We obtained 100 sets of data about indoor and outdoor particulate mass concentration through experimental measurements, so we can get 100 sets of instantaneous I/O values:

$$
I O_{t}=\frac{C_{i}}{C_{o}}
$$

Continuous stacking can be transformed into integral, so that the average I/0 value of a certain period of time can be calculated by integral formula (2), which is as follows:

$$
I O_{T}=\frac{\int_{T} C_{i}(t) d t}{\int_{T} C_{o}(t) d t}
$$

Method two: linear regression fitting

The method is to use the Outdoor particulate matter concentrationas the independent variable, and the indoor particulate matter concentration is the dependent variable. Then the value of the indoor and outdoor particulate concentration ratio can be obtained by linear regression fitting. If the fitting line is close to a straight line, it can be explained that the concentration of indoor and outdoor particles is closely related. Fig. 1 shows the indoor and outdoor particulate matter concentration linear regression.

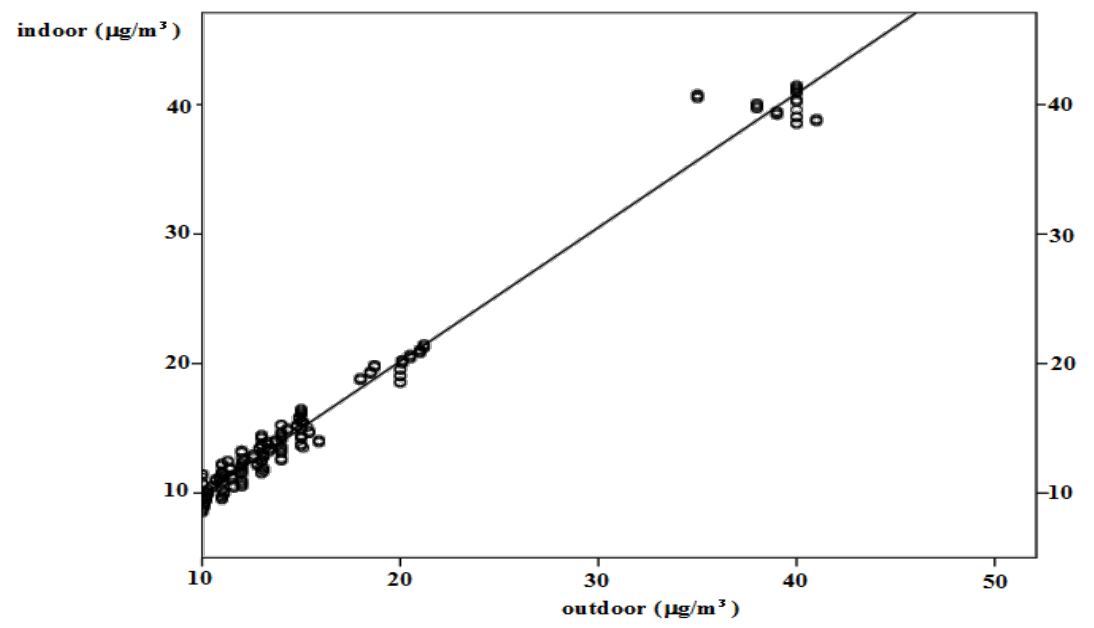

Fig. 1 Linear regression fitting of indoor and outdoor particulate matter

Correlation analysis of indoor and outdoor particle concentration. Pearson correlation coefficient is used to describe the linear correlation of two variables. The correlation coefficients are represented by $R$. The value of $R$ is between -1 and 1 . If $R$ is positive, it indicates that the two variables are positively correlated. If $\mathrm{R}$ is negative, it shows that the two variables are negatively correlated. If $\mathrm{R}$ equals 0 , it represents there is nocorrelation between the two variables.

\begin{tabular}{|c|c|c|}
\hline & $\begin{array}{l}\text { Indoor and outdoor PM2.5 } \\
\text { concentration ratio }\end{array}$ & $\begin{array}{l}\text { Indoor and outdoor } \\
\text { concentration ratio }\end{array}$ \\
\hline Integral method & 0.910 & 0.922 \\
\hline Linear regression & 0.921 & 0.942 \\
\hline
\end{tabular}

Table 1 Indoor and outdoor particulate matter concentration ratio

As Table 1 shows, the I/O ratio measured by the two methods is all above 0.9. Therefore, a conclusion can be drawn that the concentration level of indoor and outdoor particles is very close, and the same as their relationships.

The results of correlation analysis by software SPSS are shown as Table 2 and Table 3: 
Table 2 Correlation analysis of PM2.5

\begin{tabular}{ccc}
\hline Pearson Correlation & Outdoor Pm2.5 & Indoor Pm2.5 \\
\hline Outdoor Pm2.5 & 1 & 0.938 \\
Indoor Pm2.5 & 0.938 & 1 \\
\hline
\end{tabular}

Table 3 Correlation analysis of PM10

\begin{tabular}{ccc}
\hline Pearson Correlation & Outdoor Pm10 & Indoor Pm10 \\
\hline Outdoor Pm10 & 1 & 0.953 \\
Indoor Pm10 & 0.953 & 1 \\
\hline
\end{tabular}

As Table 2and Table 3 show, the indoor and outdoor correlation coefficient of PM2.5 and PM10 are 0.938 and 0.953 . It can be seen that outdoor pollution sources has huge effects on indoor particulate matter concentration level. For further, outdoor pollution is the most important contribution of indoor pollution.

\section{The change of particle concentration in the whole day}

The mass concentration of particulate matter is one of the physical properties of particulate matter. It is an important standard to measure the level of particulate matter concentration and an important basis for judging the air quality. This section selects the students' apartments as the research sites.

The whole day was divided into two periods: the day is from 6:30am to 6:30pm, and the night is from 6:31pm to 6:29am of the next day. Indoor particulate matter concentration level is described by following values:

Table 4 Indoor particulate pollution levels

\begin{tabular}{llllll}
\hline & Time slot & Minimal value & Maximum value & Mean & Standard deviation \\
\hline PM2.5( $\left.\mu \mathrm{g} / \mathrm{m}^{3}\right)$ & Night & 5 & 163 & 65.48 & 43.219 \\
& Day & 4 & 155 & 65.51 & 50.295 \\
& 24h & 4 & 163 & 65.50 & 46.947 \\
PM10 $\left(\mu \mathrm{g} / \mathrm{m}^{3}\right)$ & Night & 8 & 341 & 110.63 & 82.158 \\
& Day & 6 & 336 & 119.09 & 100.212 \\
& 24h & 6 & 341 & 115.06 & 92.091 \\
\hline
\end{tabular}

From Table 4, it can be seen that the concentration of the night is lower than that of the day. However, the average concentration of daytime and night has no obvious difference by $\mathrm{T}$ test.

\section{The comparison of the concentration of PM2.5 in typical places of Campus}

Representative places in the campus were selected to draw the column chart. It reflects the concentration of particulate matter at different locations at the same time, as is shown in Fig. 2: 


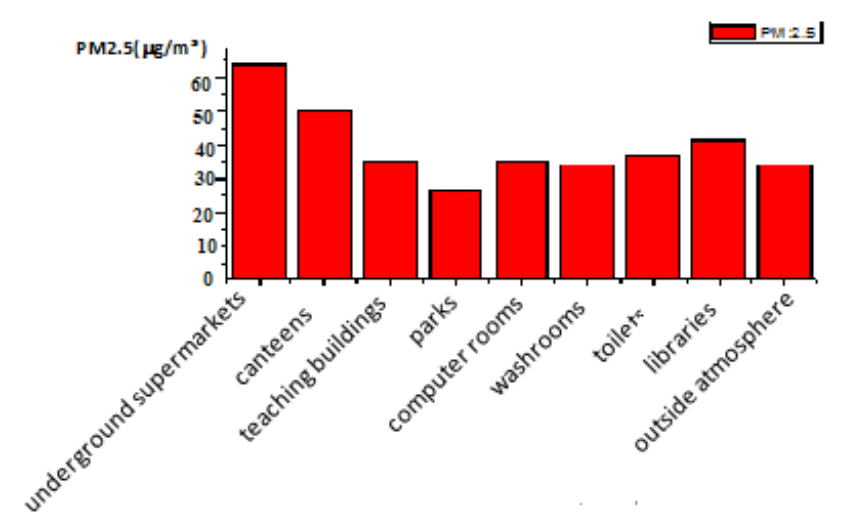

Fig. 2 Mass concentration of PM2.5 in typical places of campus

From Fig. 2, it can be seen that particulate matter concentration of the campus underground places and canteens are significantly high. It even can reach two to three times of the outdoor concentration of particulate matter. Therefore, it can be concluded that air without circulation sometimes increase the concentration of PM2.5, and cooking can become a new pollution source to some extent. Contrary to underground places and canteens, the concentration of particulate matter in the park has improved compared with the outdoor atmosphere. Maybe the park's flowers and trees have played a role in the purification of air.

\section{Summary}

Through the analysis of above three parts, some conclusions can be drawn as follows:

(1)In the building of no indoor pollution sources, indoor and outdoor particulate concentration level is closely related. The correlation coefficient reaches 0.9 . Outdoor particulate pollutants are the main source of indoor particulate matter.

(2) Particles concentrations of underground places and cooking places are high and can reach two to three times of the outdoor concentration. Therefore, it is necessary to ventilate timely to reduce the content of particulate matter in the underground places and canteens.

(3) There was no significant difference in the average particle concentration between the daytime and night.

\section{Acknowledgements}

This research has been supported by "Study on air pollutants of the dormitory building" (20142099), which belongs to the Innovation and Entrepreneurship Program for College Students in North China electric power university.

\section{References}

[1] T.F. Mar, G.A. Norris, J.Q. Koenig, Associations between air pollution and mortality in Phoenix, J. Environ Health Perspect. 108 (2000) 347-353.

[2] R.D. Brook, S. Rajagopalan, C.A. Pope, Particulate matter air pollution and cardiovascular disease: An update to the scientific statement from the American Heart Association, J. Circulation. 121 (2010) 2331-2378.

[3] C. Monn, Exposure assessment of air pollutants: A review on spatial heterogeneity and indoor/outdoor/personal exposure to suspended particulate matter, nitrogen dioxide and ozone, J. Atmospheric Environment. 35 (2001) 1-32.

[4] Information on http://www.doc88.com/p-6681186329756.html 